\title{
Failure criteria for real-time assessment of ductile cast irons subjected to various loading conditions
}

\author{
Danilo D'Angela ${ }^{1}$, Marianna Ercolino ${ }^{1}$, Costanzo Bellini ${ }^{2}$, Vittorio Di Cocco $^{2}$ and \\ Francesco lacoviello² \\ ${ }^{1}$ School of Engineering, University of Greenwich, Chatham, United Kingdom \\ ${ }^{2}$ Department of Civil and Mechanical Engineering, University of Cassino and Southern Lazio, Cassino, \\ Italy \\ E-mail: M.Ercolino@gre.ac.uk
}

\begin{abstract}
The paper presents an innovative approach for the damage assessment of ductile cast irons by using a probabilistic-based methodology. The study is based on the experimental results of acoustic emissions tests performed on pearlitic ductile cast irons subjected to both monotonic and fatigue tensile loading. The information entropy of the acoustic emissions data is confirmed to be well correlated to both the damage progress and the occurrence of the incipient failure. Robust failure criteria are finally provided for real-time assessment in structural health monitoring applications.
\end{abstract}

Keywords: acoustic emission (AE), ductile cast iron (DCI), fatigue, failure criteria, structural health monitoring (SHM)

\section{Introduction}

Structural health monitoring (SHM) of critical structures, such as bridges, pipelines, and power industry facilities, represents an issue of great interest [1,2]. The deterioration of the structural integrity of such systems affects both public safety and the international economy. Metallic fracturecritical structures are typically subjected to repeated loading within aggressive environmental conditions, and the monitoring of their state of health is critical for retaining their performance $[3,4]$. Ductile cast irons (DCI) were developed in the $40 \mathrm{~s}$, and they are widely used in civil, mechanical, and industrial engineering applications, such as pipelines, wind turbines, machinery and automotive components. The microstructure of DCIs consists of graphite nodules (or spheroids) that are embedded within an iron matrix. Both the stiffness and strength of DCIs mainly depend on the matrix, which gives the name to the DCI (e.g., ferritic or pearlitic DCI) [5]. The damage mechanisms typically initiate within the nodules (or at their interfaces with the matrix) at early stages of the stress-strain behaviour of the material, e.g., far below the yielding condition [6,7]. Recent studies [8,9] proved that DCIs might exhibit a linear response even though permanent damage is occurring within their microstructure. This peculiarity makes the damage assessment of this material more challenging.

The rapid energy releases associated with damage occurring in solids typically produces elastic waves, which are classified as acoustic emissions (AEs) for their typical frequency content. AEs are typically detected by special sensors attached to the structural elements; the recorded AE signals contain information about the occurring damage. Several studies demonstrate that the assessment of the features of the $\mathrm{AE}$ waves allows identifying damage in different structures and under various loading conditions [10-15]. A schematic acoustic waveform with highlighted hit-driven $\mathrm{AE}$ features is shown in Figure 1 [16].

The main hit-driven AE features (Figure 1) are defined for a single AE hit. In particular, AE hits are identified when the 
waveform amplitude exceeds a given threshold, and the AE features can be defined accordingly.

\subsection{Literature review}

Several studies proved that $\mathrm{AE}$ testing can be reliable for the assessment of fracture and fatigue phenomena in metals $[12,14,15,17,18]$. The damage assessment of DCIs by means of $\mathrm{AE}$ technique can be quite challenging due to the complex microstructure of the material [5,9], the chaotic nature of the acoustic phenomena $[19,20]$, and the noise-disturbance typically affecting the data detection [16,21]. Only few studies investigated this problem. Carpenter and Zhu [22] correlated the compressive behaviour of ferritic DCIs to the AE activity. Shen et al. [23] performed AE tests on a variety of grey cast irons; they found the typical frequency content ranges of the acoustic activity as well as they defined the threshold values of the main AE features associated with fracture. Sjögren and Svensson [24] investigated the damage occurring in pearlitic DCIs, proving that acoustic activity is associated with damage initiation and propagation. Kietov et al. [25] defined a correlation between the AE features and the fracture area, as well as they [26] proved that plastic response generates significant AE activity. Those past studies demonstrated the possibility to detect the damage in DCIs by the AE testing. However, they did not define quantitative damage correlations that are suitable for real-time SHM purposes.

The chaotic nature of the acoustic phenomena associated with structural damage/degradation has been recently addressed in the literature by the evaluation of the information entropy of the AE data, namely the AE entropy. The classical formulation of the information entropy was developed by the seminal work of Shannon [27]. The mere generation of the acoustic activity already reflects the microstructural disorder [28], and this explains the reason why the evaluation of the AE entropy has shown so much potential for structural damage assessment [20,29-31]. The application of this methodology to the context of the AE testing of metallic structures is quite recent, but the related literature is rapidly growing. $\mathrm{AE}$ entropy can be correlated to damage more efficiently than the basic AE features [32]. Acoustic entropy potentially has a clear trend along with the damage evolution, and the main features were found to be not mainly depending on the specific material/application [20,30,31]. A relative (or conditional) measure of AE entropy was also developed by applying the Kullback-Leibler divergence [33]. Relative AE entropy describes how the probability distribution of current and previous AE data differ, and it can also be considered as a current-to-previous conditional entropy measure [20].

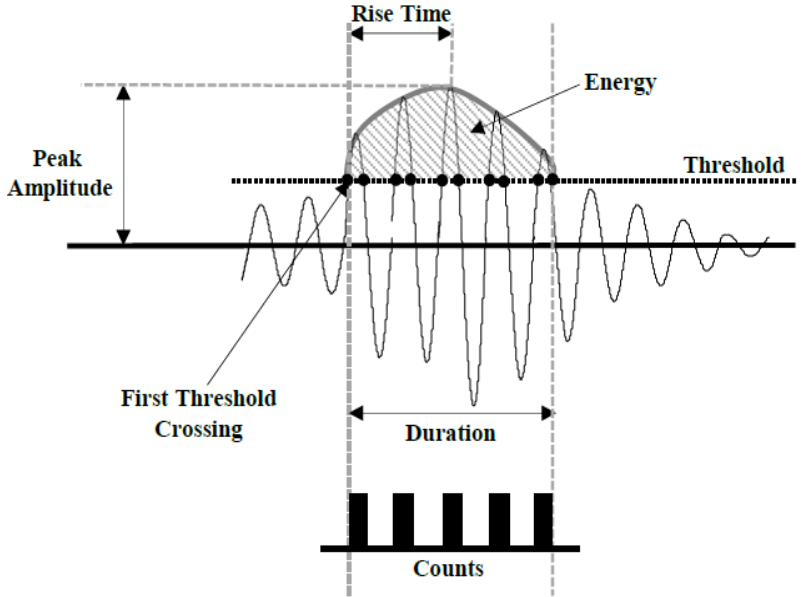

Figure 1. Schematic AE waveform, AE hit, and main related AE features (hit-driven data) [16].

Both entropy formulations were recently assessed for SHM purposes [8,17,34], and some qualitative findings were identified. However, the potential of the methodology is still far to be fully achieved. Furthermore, such an approach has never been applied for the assessment of DCIs.

\subsection{Motivations, scope, and significance}

DCIs exhibit significant microstructural damage corresponding to levels of stress that are lower than the elastic limit $[8,9]$. This is due to the microdamage mechanisms affecting the nodules as well as their interfaces with the matrix. The microstructural damage releases stress energy, and it generates elastic waves that carry information about the ongoing damage. The detection/analysis of the AE signals allows assessing the damage in such complex materials, while traditional monitoring approaches do not allow such an efficient characterisation since they are based on macroscopic features. Moreover, such an approach permits real-time assessment, and it can be implemented in SHM processes.

The paper presents AE tests on pearlitic DCIs under various fatigue loading conditions. The information entropy of the AE data was correlated to both damage initiation and development. The performance-based assessment approach typically used in structural engineering $[35,36]$ is extended to the presented tests and to previously performed tests $[8,9]$. Robust criteria are finally defined for real-time health monitoring of DCI structures under various loading conditions.

The study enhances the experimental damage assessment of DCIs. The damage assessment was improved by providing (a) reliable AE testing methods/arrangement (b) extended literature database, (c) innovative data analysis approaches for SHM based on performance-based assessment, and (d) quantitative failure criteria, which will be suitable for realtime SHM applications. 


\section{Methodology}

Tensile tests were carried out on DCIs under cyclic loading. $\mathrm{AE}$ testing was performed according to the parameter-based approach [37]. The approach is widely used for real-time SHM purposes since a relatively reduced amount of data has to be stored, and the data analysis can be performed remotely in real-time. Moreover, several applications proved the reliability of the approach and supplied guidance on testing and analysis techniques.

The AE data were preliminarily assessed by considering the traditional analysis techniques, e.g., historical plots and correlation analysis (e.g., $[9,12,13,21])$. However, such basic approaches are usually not capable of identifying the damage since they are affected by noise disturbance. The analysis of the AE signals was performed by evaluating the entropy of the AE data, according to Shannon [27] and Kullback-Leibler [33] formulations. Even though such an approach has been applied in few past studies [30,31,34], the AE entropy has never been applied to the case of DCIs under fatigue loading. The study used the AE testing technique to assess a complex material with an innovative testing arrangement. Moreover, the investigated damage is related to the micromechanisms, which are occurring at a low level of stresses. A performancebased approach (PBA) was applied to assess the experimental data, according to the typical approaches used in structural and earthquake engineering [35,36]. The statistical-based assessment (fragility curves) can take into account the uncertainty associated with the loading/testing conditions.

\subsection{Material and specimens}

Microtensile specimens made of a fully pearlitic DCI (EN GJS700-2) were tested. Pearlitic DCIs have been less investigated than other types of irons such as ferritic DCIs, although they are widely used in several engineering applications because of their high strength and moderate ductility [5]. The chemical composition of the material is reported in Table 1, and the geometry of the specimens is shown in Figure 2. Microtensile are among the simplest specimens for tensile testing. They have the potential to provide uniaxial stress-strain data that is representative of macroscopic behaviour. Their small dimension allows performing SEM analysis, even under in situ conditions (e.g., $[5,9])$. These specimens are widely used in the literature to assess DCIs (e.g., [5,6,9,38]).

The material has a nodularity larger than $85 \%$ with a nodular volume fraction ranging within $9-10 \%$. The microtensile specimens were obtained by a cylindrical billet having a diameter equal to $80 \mathrm{~mm}$. The nominal tensile strength $\sigma_{u}$ of the material was $700 \mathrm{MPa}$.

\subsection{Experimental set-up}

Cyclic tensile tests were performed by means of a rotating motor. The specimen strain was controlled by a linear variable differential transformer (LVDT), whereas two miniature load cells estimated the applied load. Scanning electron microscopy (SEM) analysis of the specimen lateral surfaces was performed after the failure of the specimens was reached. In particular, 15 nodules were selected for each specimen in the vicinity of the fracture surface.

The testing machine consisted of a tensile holder (Figure 3.a) that included the housing of the specimen and the loading cells. The tensile holder was connected to the rotating motor and the differential transformer, as it is depicted in Figure 3.b. The whole tensile testing machine was designed and patented by Iacoviello et al. [39], and it was used in several other studies (e.g., $[5,6,8,9])$. AE testing was performed by means of two inter-connected 1283 USB AE Node systems and two pre-amplified ultra-low noise sensors ( $P K 15 I)$.

The Node system has the full capacities of a last-generation multichannel system, but it is portable and allows a more versatile use (e.g., field monitoring). PK15I sensor has a frequency response ranging within $100-450 \mathrm{kHz}$, with peak resonance at $150 \mathrm{kHz}$.

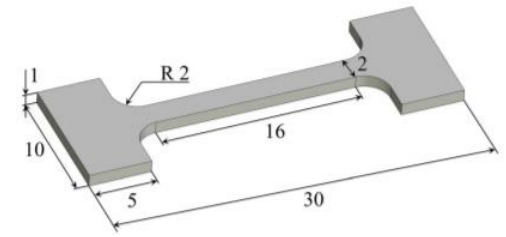

Figure 2. Geometry of the microtensile specimens [5].

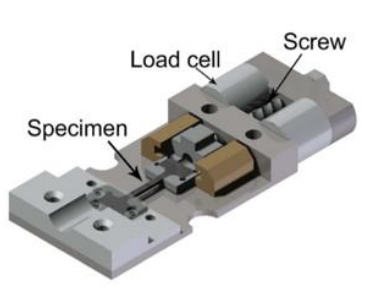

(a)

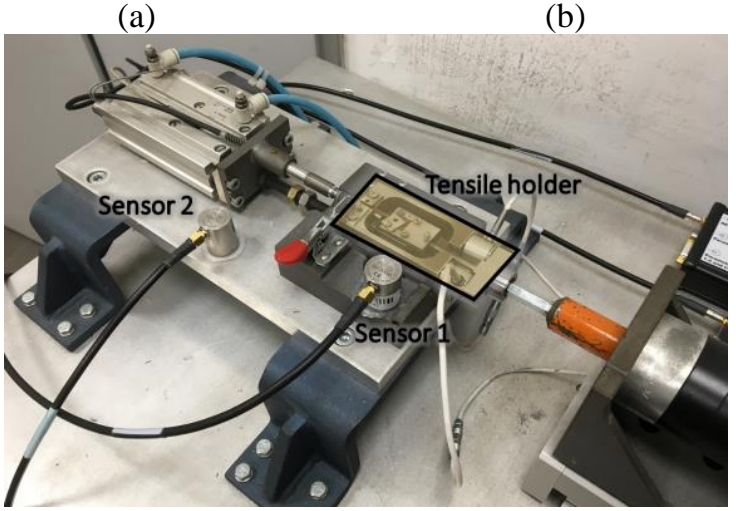

(c)

Figure 3. Testing equipment (a) tensile holder, (b) whole tensile system, and (c) testing set-up including the sensors $[5,9]$. 
Table 1. Chemical composition in wt\% for fully pearlitic DCI (EN GJS700-2).

\begin{tabular}{lllllllllll}
\hline $\mathbf{C}$ & $\mathbf{S i}$ & $\mathbf{M n}$ & $\mathbf{S}$ & $\mathbf{P}$ & $\mathbf{C u}$ & $\mathbf{M o}$ & $\mathbf{N i}$ & $\mathbf{C r}$ & $\mathbf{M g}$ & $\mathbf{S n}$ \\
\hline 3.59 & 2.65 & 0.19 & 0.012 & 0.028 & 0.004 & 0.004 & 0.029 & 0.061 & 0.060 & 0.098 \\
\hline
\end{tabular}

Table 2. Testing procedure.

\begin{tabular}{|c|c|c|c|c|}
\hline \multirow{2}{*}{ test ID } & $\sigma_{\max }$ & $\sigma_{\min }$ & $\boldsymbol{R}$ & strain rate \\
\hline & {$[\mathrm{MPa}]$} & {$[\mathrm{MPa}]$} & {$[-]$} & {$\left[\mathrm{s}^{-1}\right]$} \\
\hline$C 1$ & $200,300,400,500,600,700$ & 100 & $0.5,0.33,0.33,0.25,0.17,0.14$ & \multirow{3}{*}{0.1} \\
\hline$C 2$ & 700 & 350 & 0.5 & \\
\hline C3 & 700 & 70 & 0.1 & \\
\hline
\end{tabular}

The sensor features allowed to neglect the low frequencies (e.g., lower than $50 \mathrm{kHz}$ ), which are typical of noise and disturbance (e.g., [40]); the frequency resonance covered the typical frequencies of sensitivity associated with the tested material (e.g., [25]). The software $A E$ win $^{\text {TM }}$ was used to store and process the AEs [41]. The whole testing arrangement is shown in Figure 3.c.

Sensor 1 was located close to the specimen, whereas sensor 2 was located on the supporting base of the tensile machine. Location of sensor 1 was aimed at maximising the detection of genuine acoustic activity, whereas sensor 2 was primarily intended to detect the noise disturbance due to the support vibrations.

This arrangement was derived from a previous study performed by the authors on monotonic testing [9], in which it was proven that sensor 1 detected genuine damage signals, whereas sensor 2 was associated with vibration and noise disturbance. Sensor 2 was used to cover two essential aspects: (a) checking whether the acoustic features related to the monotonic response [9] were also consistent during the cyclic tests, and (b) producing new data to perform a further study aimed at the quantitative characterisation of the noise features.

Both sensors were coupled to the supports by means of a thin layer of silicone glue (Loctite 595).

The optimum AE testing parameters were defined according to mock tests as well as by considering literature applications $[9,12,29,40]$. The amplitude threshold was set equal to $45 \mathrm{~dB}$, and the peak definition time (PDT), the hit definition time (HDT), and the hit lockout time (HLT) were set equal to 200,800 , and $1000 \mu$ s, respectively

\subsection{Experimental procedure}

Three specimens were tested under cyclic loading. Some past studies tested the same number of specimens with similar applications (e.g., [9.37]). In particular, the final testing parameters were selected according to the results of preliminary mock tests performed on various DCIs by also using alternative testing arrangements. Those mock tests were also performed considering the same material/testing condition as in the final tests, and their results were consistent with the definite test ones.

Three loading procedures were considered, according to Table 2 . The tests had different loading program to assess the variability of the loading conditions.

Test $C 1$ had incremental maximum cyclic stress $\sigma_{\max }$ increasing from 200 to $700 \mathrm{MPa}$ through increments of 100 $\mathrm{MPa}$ and fixed minimum cyclic stress $\sigma_{\min }$ equal to $100 \mathrm{MPa}$ $\left(R=\sigma_{\text {max }} / \sigma_{\min }=0.5,0.33,0.25,0.17,0.14\right)$. Test $C 2 \mathrm{had}$ constant $\sigma_{\max }$ equal to $700 \mathrm{MPa}$ and $\sigma_{\min }$ equal to $350 \mathrm{MPa}$ $(\mathrm{R}=0.5)$, whereas test $C 3$ had constant $\sigma_{\max }$ equal to $700 \mathrm{MPa}$ and $\sigma_{\min }$ equal to $70 \mathrm{MPa}(R=0.1)$. Test $C l$ was related to $R$ decreasing from 0.50 to 0.14 , whereas tests $C 2$ and $C 3$ approximately covered the limits of this range.

The tests were performed under strain control, with a strain rate set equal to $0.1 \mathrm{~s}^{-1}$ for all fatigue tests. This rate is relatively fast for static tests (e.g., [42]), and it was chosen to investigate the response of the material for relatively quick strain variations.

\subsection{AE entropy evaluation}

Shannon and Kullback-Leibler AE entropies $\left(S_{E}\right.$ and $\left.S_{E, r}\right)$ are defined in Equations 1 and 2, respectively, where $\boldsymbol{p}_{\boldsymbol{i}}$ defines the probability mass distribution vector related to the $i^{\text {th }} \mathrm{AE}$ hit (or equivalently $i^{\text {th }}$ time instant in which $\mathrm{AE}$ activity is detected). The empirical (or experimental) probability mass distribution vector is reported in Equation 3, where $n_{i}$ and $\sum n_{i}$ are counts and cumulative counts, respectively, related to the $k^{\text {th }} \mathrm{AE}$ hit.

$$
\mathrm{S}_{\mathrm{E}}=-\sum_{\mathrm{i}=1}^{\mathrm{N}} \mathrm{p}_{\mathrm{i}} \log _{2}\left(\mathrm{p}_{\mathrm{i}}\right)
$$

$$
\begin{gathered}
\mathrm{S}_{\mathrm{E}, \mathrm{r}}=\mathrm{S}_{\mathrm{E}}\left(\mathrm{p}_{\mathrm{i}} \mid \mathrm{p}_{\mathrm{i}-1}\right)=-\sum_{\mathrm{i}=1}^{\mathrm{N}} \mathrm{p}_{\mathrm{i}} \log _{2}\left(\frac{\mathrm{p}_{\mathrm{i}}}{\mathrm{p}_{\mathrm{i}-1}}\right) \\
\mathbf{p}_{\mathrm{i}}=\left\{\frac{\mathrm{n}_{1}}{\sum \mathrm{n}_{\mathrm{i}}}, \frac{\mathrm{n}_{2}}{\sum \mathrm{n}_{\mathrm{i}}}, \ldots, \frac{\mathrm{n}_{\mathrm{i}}}{\sum \mathrm{n}_{\mathrm{i}}}\right\}
\end{gathered}
$$




\subsection{Performance-based assessment}

The AE entropies associated with the incipient failure condition were processed according to the PBA: the fragility assessment. This application aims at producing robust damage criteria for SHM. Fragility evaluation is an advanced methodology for the assessment of engineering systems affected by uncertainty concerning their capacity/demand $[35,36]$.

Fragility is traditionally defined as the probability that a damage state (DS) is reached given a particular engineering demand parameter (EDP) value.

EDPs are quantities associated with the structural response of a system that are correlated to DSs. Such an approach is included within the traditional framework of the performancebased earthquake and structural engineering [35,36]. EDPs are usually defined by guidelines [43] and past research studies $[44,45]$. For instance, structural elements such as reinforced concrete columns are sensitive to both element chord rotation and inter-storey drift ratio (relative displacement between the stories normalised over the storey height), and such parameters are typically used as EDPs for seismic assessment. However, EDPs and fragility curves have never been used in the case of SHM on DCIs or for similar applications. Therefore, the definition/selection of the EDPs was based on the experimental response of the components and the exhibited damage sensitivity, and the used EDPs are defined after the presentation of the results.

The development of the fragility methodology was based on the early work of Cornel [46] as well as on other pioneering studies (e.g., [47,48] among many others). The lognormal model proposed by Porter [35,36] was considered in the present work. Equation 4 shows the fragility function $F_{D S}$ according to the considered formalism, i.e., associated with DS and computed considering EDP. In particular, $\Phi$ defines the cumulative distribution function for the standard normal distribution, and $x_{m}(\beta)$ defines the median (logarithmic standard deviation) of $F_{D S}$, reported in Equations (5) and (6). $M$ is the number of specimens (or tests), and $r_{i}$ is the lowest threshold value of EDP corresponding to the occurring of DS for the $i^{\text {th }}$ specimen (test).

$$
\begin{gathered}
F_{D S}(E D P)=\Phi\left(\frac{\log \left(\frac{E D P}{x_{m}}\right)}{\beta}\right) \\
x_{m}=\exp \left(\frac{1}{M} \sum_{i=1}^{M} r_{i}\right) \\
\beta=\sqrt{\frac{1}{M-1} \sum_{i=1}^{M}\left[\log \left(\frac{r_{i}}{x_{m}}\right)\right]^{2}}
\end{gathered}
$$

\section{Results and discussion}

The results of the monotonic tests previously performed by the authors [9] are also described in the following for comparison purposes and to highlight the features of the mechanical and acoustic response related to the cyclic tests. Further insights into both damage mechanisms and entropy evaluation of the monotonic response are supplied. The PBA assessment (i.e., fragility curves) was also performed by considering the monotonic tests [9] and the fatigue crack growth (FCG) tests on steel and aluminium compact tension (CT) specimens performed by the authors [29].

\subsection{Macroscopic mechanical response}

The elastic limits of the monotonic response ranged in $550-600 \mathrm{MPa}$ and $6-7 \%$ in terms of engineering stress $(\sigma)$ and strain $(\varepsilon)$, respectively. A gradual yielding knee was observed after the elastic limit with ultimate strength equal to about $750 \mathrm{MPa}$ (on average), which was followed by a short softening branch in some cases. The complete fracture of the specimens defined the failure condition. Failure strain always exceeded $10 \%$, with an average value equal to about $11 \%$.

Figure 4 shows the mechanical response related to cyclic tests, i.e., (a) strain $\varepsilon$ versus time and (b) stress $\sigma$ versus strain $\varepsilon$. Tests $C 1, C 2$, and $C 3$ exhibited failure at 6,5 , and $\sim 600$ cycles, respectively, whereas the failure strain values were equal to $9.8,8.4$, and $9.7 \%$. In particular, Figure 4 .a shows the first 300 seconds in order to compare the first cycle(s) loading program among the different tests. The failure cycles in test C3 ( 600 cycles) are much larger than in the other tests. It is recalled that the loading procedures were stress-based even though strain-controlled, i.e., the planned stress program was applied by strain increments (with approximately constant strain rate).

The elastic stiffness related to the superior envelope related to test $C l$ was significantly small due to the unloading/loading stages over the elastic response, as it can be seen in Figure 4.b. The unloading/loading path stiffness was not significantly affected by the different loading programs as well as by the damage accumulation. The energy dissipated through the hysteretic process slightly increased over the damage accumulation according to a nonmonotonic way, as it can be seen in Figure 4.b by considering test $C 1$.

The material exhibited significant residual post-unloading strain even at very low stresses (e.g., $300 \mathrm{MPa}$ ). The reduction of the failure strain due to cyclic loading was different between $C 1 / C 3$ tests and $C 2$. This phenomenon was partially expected given the different order of magnitude of the related fatigue lives. In particular, $\mathrm{Cl} / \mathrm{C} 3$ failure strain was about $10 \%$ smaller than the (average) monotonic ones, whereas $C 2$ one resulted in about $25 \%$ of reduction. 


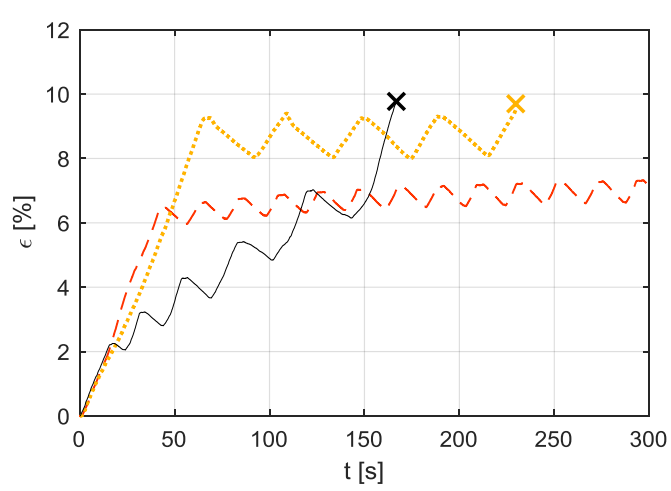

(a)

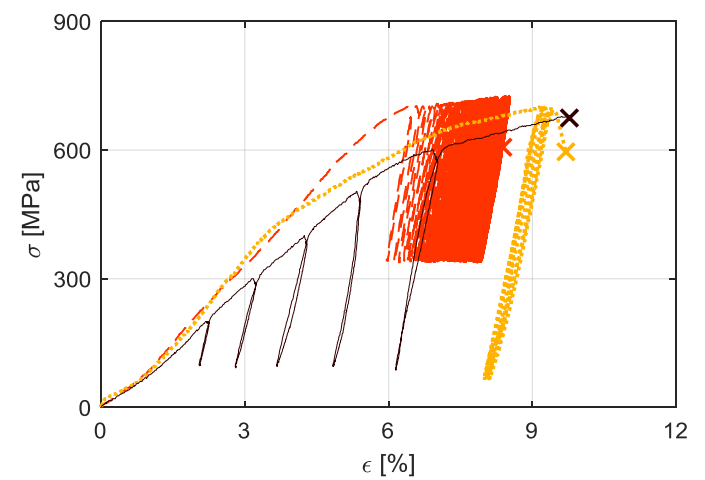

(b)

$$
-\sigma_{\mathrm{C} 1}---\sigma_{\mathrm{C} 2} \cdots \cdots \cdots \cdot \sigma_{\mathrm{C} 3}
$$

Figure 4. Mechanical response during cyclic tests: (a) strain $\varepsilon$ versus time and (b) stress $\sigma$ versus strain $\varepsilon$.

\subsection{Damage micromechanisms}

The damage process of the cyclic tests evolved with multiple micromechanisms, similarly to the monotonic response [9]. Only the most relevant nodules are described in the paper since (a) similar patterns were observed over the different nodules and (b) the focus of the study is not on the damage characterisation. Therefore, the following comments can be considered as representative for all tests. Overall, the damage initiated within the nodules (and at their interfaces) over the elastic range when the stress was in the range of 450 - $550 \mathrm{MPa}$. The cracks extended their width and developed within the nodules, causing the beginning of the early plastic response. The cracks at the nodule-matrix interface propagated within the matrix corresponding to significant plastic deformation. In some cases, such cracks formed bands that finally coalesced into the fracture surfaces.

The following elementary micromechanisms were identified at the post-failure condition: (a) onion-like (OL), (b) disgregation (D), (c) matrix-nodule debonding (DB), and (d) matrix-nodule crack (MC). Figure 5 and Figure 6 show the SEM analysis corresponding to the post-failure conditions of four representative nodules related to monotonic and cyclic tests, respectively. Such nodules were related to test $C 2$, and very similar responses were found concerning the other tests.
In most of the cases, one or two mechanisms were more significant than the other(s), as it can be observed in Figure 5.b where $\mathrm{OL}$ and $\mathrm{DB}$ are more developed than D and MC.

In nodules in which significant DB occurred, the other mechanisms often had minor extension/development, as it can be seen in Figure 5.c and Figure 6.a, b, and c. In some cases, the same cracks were associated with more than a mechanism, often including OL, as Figure 5.a, b, and Figure 6.c show with regard to D, DB, and DB, respectively. Nodules closer to the fracture surface exhibited more severe damage, with severe $\mathrm{D}$, and in general larger crack widths, as it can be seen in Figure 5.d (Figure 6.d) with regard to monotonic (cyclic) tests.

The nodules exhibited less severe damage than the cyclic ones under monotonic loads with the exception of the nodules close to the fracture surface (e.g., Figure 5.d), which exhibited damage comparable to the cyclic tests (e.g., Figure 6.d). Severe debonding was more frequently observed in nodules subjected to cyclic loading. The matrix-nodule cracks found in nodules had a smaller extension and width (e.g., Figure 5.a and $b$ ) under monotonic loading than the cases under cyclic loads (Figure 5.b and c).

\subsection{Basic AE analysis}

Historical and correlation analysis of the main AE features was performed in order to identify the relevant characteristics of the activity associated with the cyclic response of the investigated material, e.g., energy or amplitude ranges along with the damage increase. Time-based stages were defined for the cyclic tests by considering fractions of the testing time $t$ over the failure time $t_{F}$, i.e., (1) $t / t_{F} \leq 0.50$, (2) $0.50<t / t_{F} \leq$ 0.80 , and (3) $0.80<t / t_{F} \leq 1.00$. This choice was motivated by the significantly different loading conditions among the cyclic tests that did not allow finding a unique alternative parameter.

Different trends were identified among the cyclic tests in terms of both the typical values of $\mathrm{AE}$ features and the time evolution. Overall, less activity was detected over test $\mathrm{Cl}$ if compared to test $C 2$ and $C 3$. Almost all $\mathrm{AE}$ events related to test $C l$ were detected prior to the failure, whereas a continuous activity was detected in tests $C 2$ and $C 3$. Copious AE activity was detected at stress levels below the maximum previously reached applied stress (both unloading and loading branches). Such evidence proved that the component response does not follow the Kaiser effect [49,50] because of the heterogeneous nature of the tested material, such as DCIs (e.g., [50]). The detected AEs are produced by some permanent damage occurring within the nodules (and at their matrix interfaces) over relatively low levels of stress. The number of counts related to the pre-failure stage of $\mathrm{Cl}$ test was significantly larger than the one related to $C 2$ and $C 3$ tests. On the contrary, in these latter cases, the activity associated with the pre-failure stage did not present evident differences if compared to the AE detected over the whole tests. 


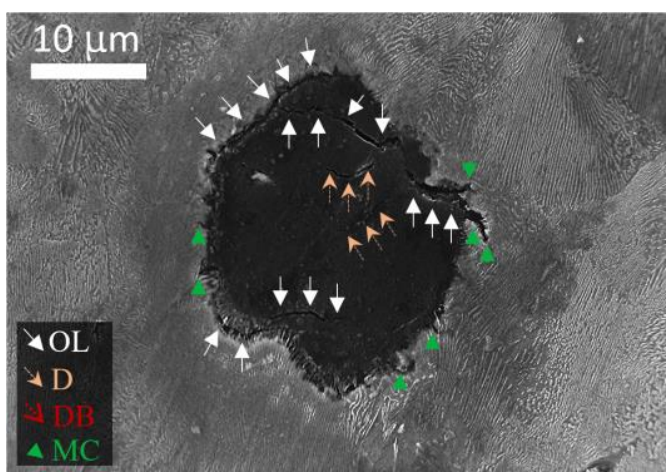

(a)

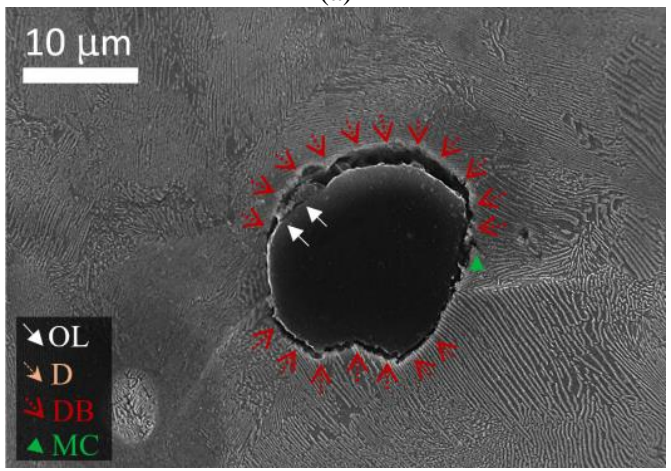

(c)

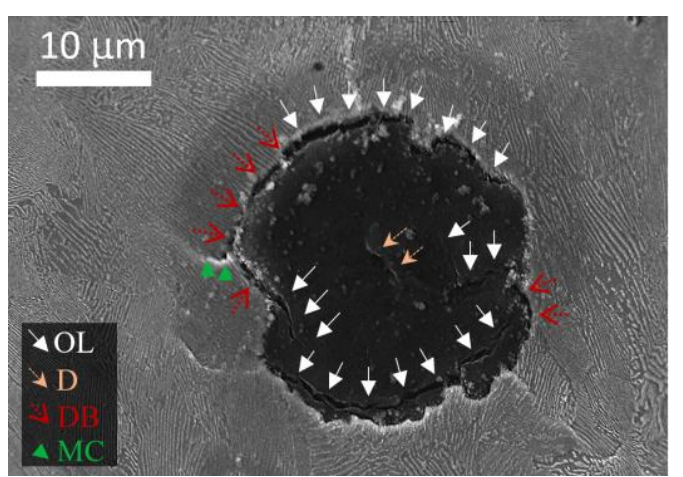

(b)

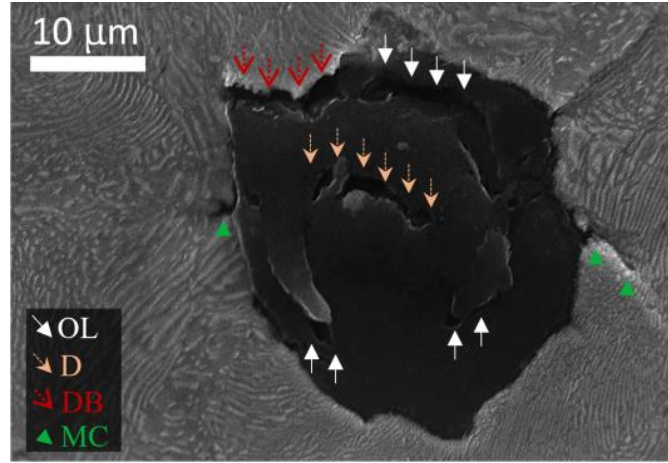

(d)

Figure 5. SEM analysis corresponding to post-failure conditions related to monotonic tests [9]. The nodule shown in (d) was significantly closer to the fracture surface than the other ones.

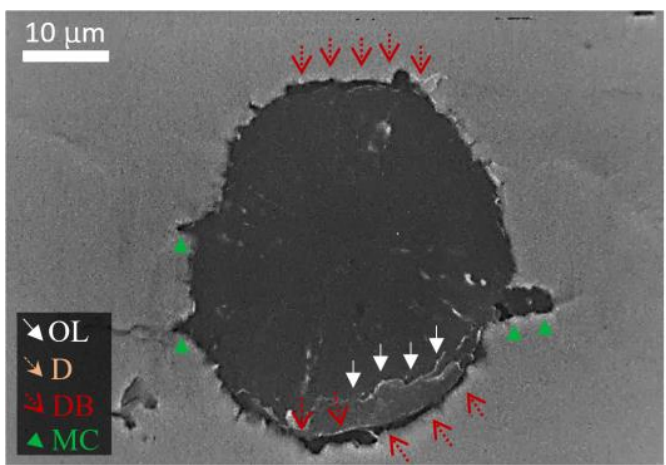

(a)

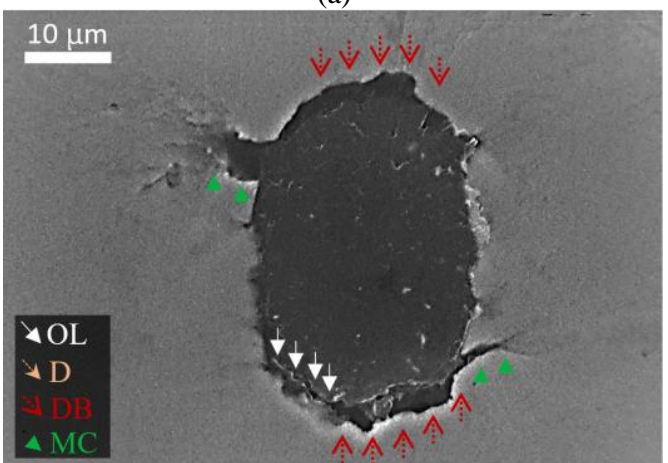

(c)

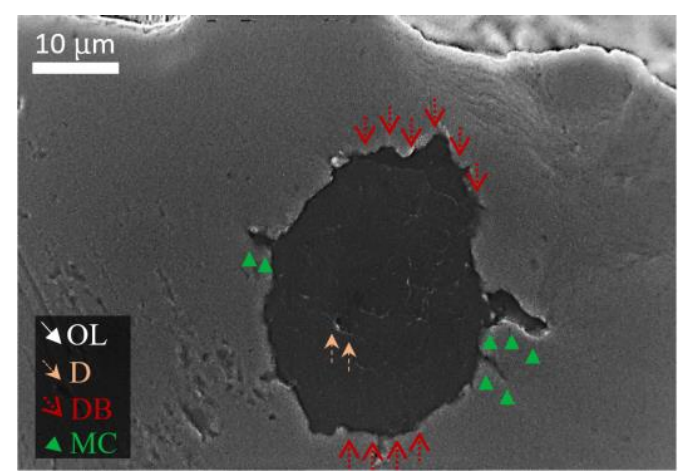

(b)

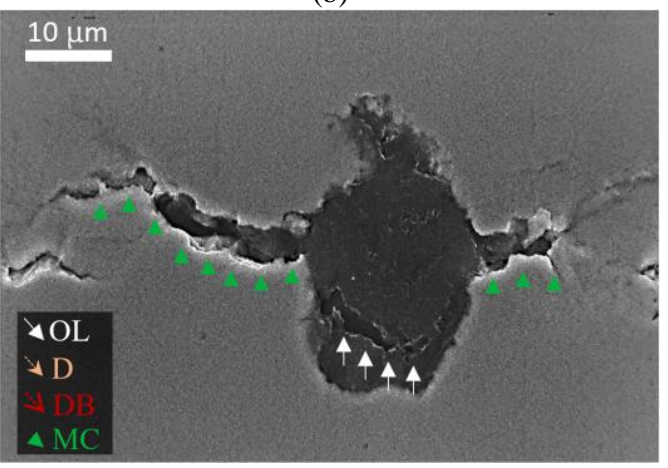

(d)

Figure 6. SEM analysis corresponding to post-failure conditions related to cyclic tests. The nodule shown in (d) was significantly closer to the fracture surface than the other ones. The depicted nodules are related to test $C 2$, and they are representative of the other tests as well. 
(1)

(a)
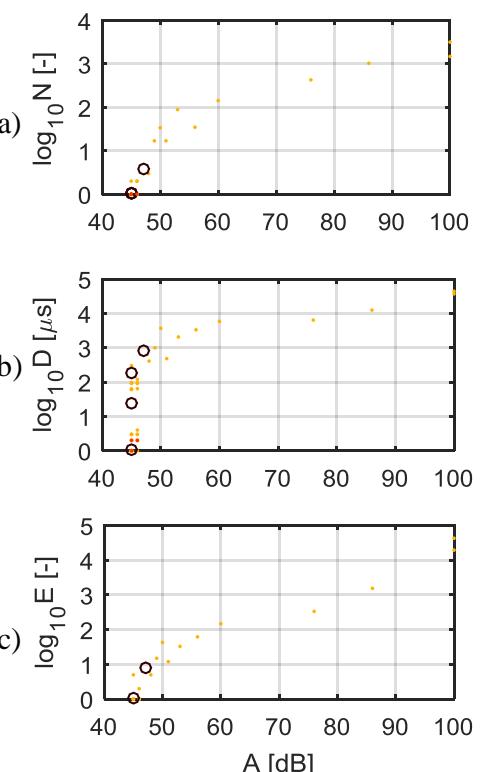

(2)
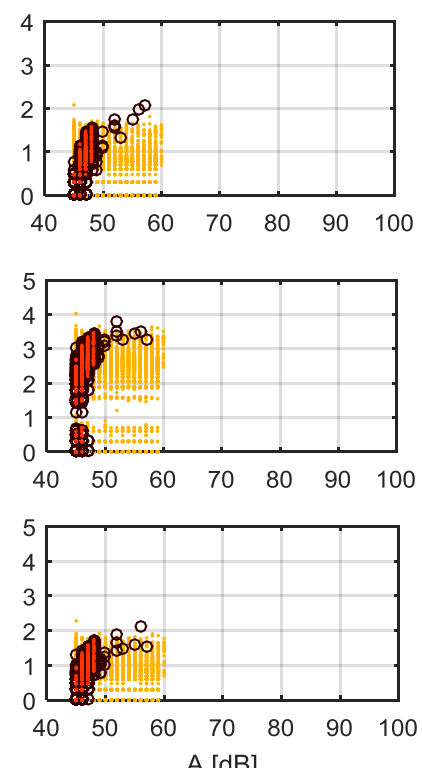

$A[\mathrm{~dB}]$
(3)
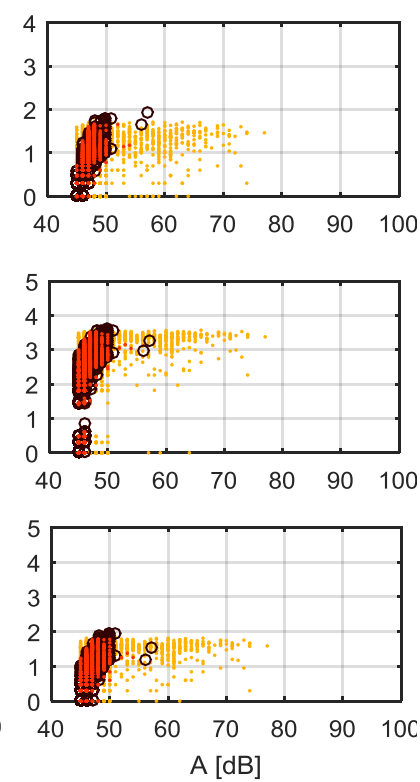

$\begin{array}{llll}\mathrm{O} & \text { stage } 1 & \text { stage } 2 & \text { stage } 3\end{array}$

Figure 7. AE correlation analysis results related to (a) $\log _{10} N$ versus $A$, (b) $\log _{10} D$ versus $A$, and (c) $\log _{10} E$ versus $A$ for tests (1) $C 1$, (2) $C 2$, and (3) $C 3$.

(a)

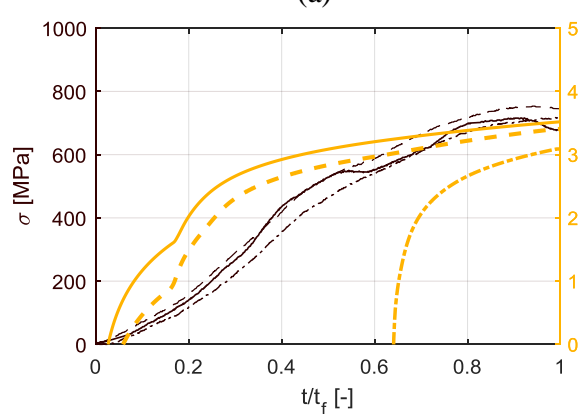

(2)

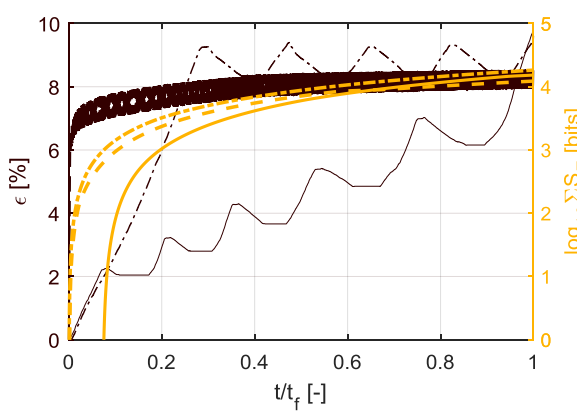

(b)
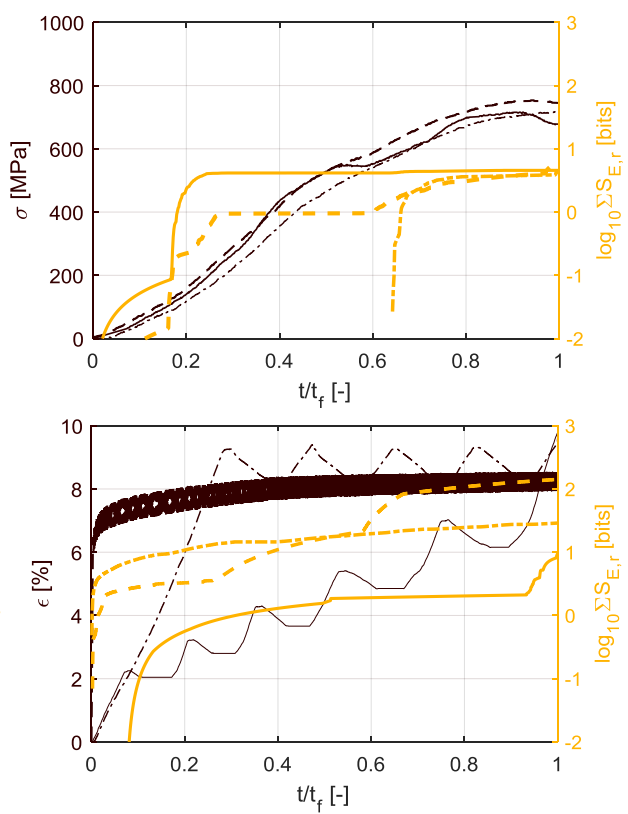

$$
\begin{array}{|r|}
\hline---M 1 / C 1 \text { [left axis] } \\
-\cdot--M 2 / C 2 \text { [left axis] } \\
\hline-M 1 / C 3 \text { [left axis] } \\
---M 2 / C 1 \text { [right axis] } \\
---M 3 / C 3 \text { [right axis] } \\
\hline
\end{array}
$$

Figure 8. AE entropies for (1) monotonic [9] and (2) cyclic tests, considering engineering stress $\sigma$ and strain $\varepsilon$ evolution, respectively, together with (a) $S_{E}$ and (b) $S_{E}$, 
The Shannon entropy values at the failure related to cyclic tests were similar among them and larger than the monotonic test ones. The relative entropy curves were overall similar in shape to the Shannon ones. The knee of the relative entropies was more abrupt and irregular than the monotonic ones, and the response was more irregular in some other parts of the curves (e.g., C1 curve significantly increased just prior to failure). Monotonic relative entropy curves were slightly more regular than cyclic ones, with particular regard to the postknee branch. The monotonic entropy values were very similar among them at the failure, whereas they had a larger dispersion in the case of cyclic tests. Cyclic relative entropies were overall larger at the failure than monotonic ones.

Both Shannon and Kullback-Leibler entropy values related to test $C 1$ are lower than the other ones over the whole testing time, especially for Kullback-Leibler entropy. This outcome might be explained by considering the significantly different loading programs between $C 1$ and $C 2 / C 3$ tests. The maximum cyclic stresses increased over the test by starting far below the nominal strength for $C l$ test. All cycles related to the other tests had maximum cyclic stress equal to nominal strength.

Figure 9 shows the relative entropy curves of the cyclic tests along with some damage conditions related to the most significant mechanical response. Clear damage correlations were identified for test $C 1$ (Figure 9.a). The loading stiffness related to the branch consequent to the previous tension peak $(\delta \sigma / \delta \varepsilon)$ regularly decreases as the curve evolves, and its value is reported as a function of the initial stiffness $\left(|\delta \sigma / \delta \varepsilon|_{0}\right)$ in Figure 9.a. The first significant stiffness drop was corresponding to the knee of the curve. The significant entropy increase in the final stage of the curve corresponds to a very reduced value of the loading stiffness $(\delta \sigma / \delta \varepsilon \leq 0.2)$, which is associated with a highly plastic behaviour (highlighted in Figure 9.a). The highly plastic behaviour can also be identified in Figure 4.b and correlated with time by considering Figure 4.a.

It was not possible to identify similar damage correlations for the other cases, even though the main mechanical stages seem to correspond to specific branches of the curves in a qualitative manner. Test $C 2$ exhibited approximately constant loading/unloading stiffness during the whole test. The superior envelope of the stress-strain curves (e.g., Figure 4.b) is the only parameter that is affected by fatigue damage accumulation. When the curve branches have a value lower than one, they were associated with linear stiffness (first loading branch) for test $C 2$ (Figure 9.b) and reduced stiffness degradation for test $C 3$ (Figure 9.c). A sudden tension drop (peak) identified in test $C 2$ corresponded to a decrease (increase) of the tangent in Figure 9.2. The first unloading branch related to test $C 2$ was associated with a horizontal tangent, whereas the other (un)loading branches were not associated with the entropy curves. The final branch related to test $C 2$ was associated with the onset of the highly plastic response, which was not observed for test $C 3$.

The amplitude of the AE signals was not larger than $50 \mathrm{~dB}$ up to the pre-failure stage for all cases. In the last stage, large amplitudes were detected, especially for $C 1$. In particular, very few events related to $C l$ presented extremely large amplitudes (e.g., $80-100 \mathrm{~dB}$ ), and some of the events associated with $C 3$ had relatively high amplitudes (e.g., $70-80 \mathrm{~dB}$ ); low amplitudes were detected over test $C 2$ $(50-60 \mathrm{~dB})$. Figure 7 shows the main AE correlation plots, i.e., (a) $\log _{10} N$ versus $A$, (b) $\log _{10} D$ versus $A$, and (c) $\log _{10} E$ versus $A$ for tests (1) $C 1$, (2) $C 2$, and (3) $C 3$.

$C 1$ test showed activity quite similar to the one related to monotonic tests performed on the same material [9]. Similarly, the AE activity related to the monotonic branch of the first cycle related to $C 2$ and $C 3$ was quite reduced and comparable to the monotonic test activity in terms of both features and time evolution. Similarities were identified by comparing tests $C 2$ and $C 3$ in terms of AE feature correlations. The three stages are correlated to different features. In particular, the activity related to stage 1 had reduced amplitude $A$, number of counts $N$, and energy $E$, as well as it is not particularly dispersed if compared to the other stages. The activity related to stage 2 was quite similar to the stage 1 , but it overall presented higher amplitude $A$, number of counts $N$, and energy $E$, as well as it is more dispersed. The AEs related to stage 3 was quite different for all tests: high amplitude $A$ and larger AE feature values with significant scattering.

\subsection{AE entropy}

Figure 8 depicts the cumulative curves related to both Shannon and Kullback-Leibler entropies $\left(\Sigma S_{E}\right.$ and $\left.\Sigma S_{E, r}\right)$ for (1) monotonic [9] and (2) cyclic tests over normalised time (i.e., testing time $t$ divided by failure time $t_{f}$ ). The stress/strain curves are plotted versus time in the same figure. The Shannon entropy curves (Figure 8.a) have a similar trend for both monotonic and cyclic tests. In particular, a short sub-vertical tangent branch was observed in the first stage of the curves; this is corresponding to the detection of the initial acoustic activity. A gradual knee (significant decrease of curve tangent) was then observed. After the knee, a sub-horizontal tangent stage was identified, with decreasing tangent over time. Very reduced tangent values were observed at the failure. In all cases, the Shannon entropy curves were smooth and quite regular. It is recalled that for the monotonic tests, the failure time was approximately the same (same loading program), whereas it was quite different among cyclic tests, comparing $C 1 / C 3$ and $C 2$ tests. However, the tangents in Figure 8 do not present the actual value given the time normalisation, and the relation among the actual tangents of the cyclic curves differs from the one observed in Figure 8.2. 


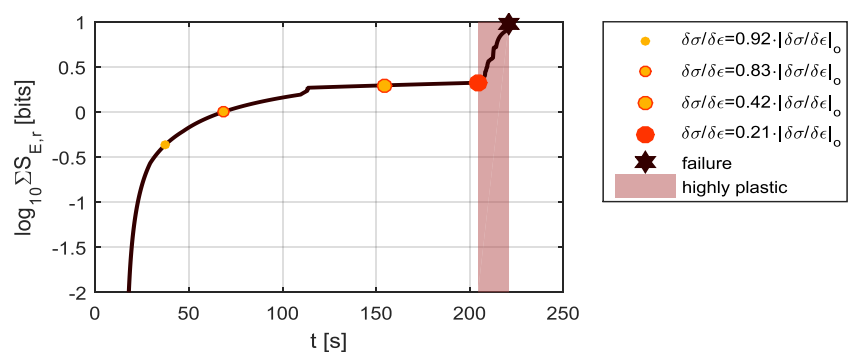

(a)

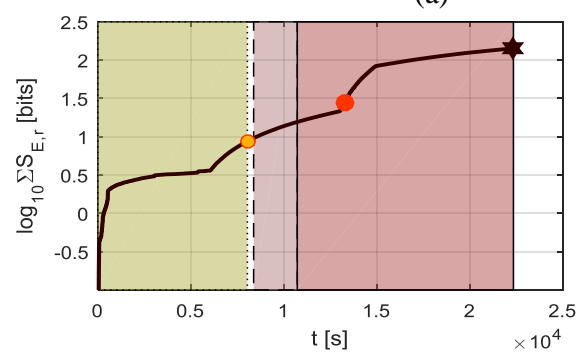

(b)

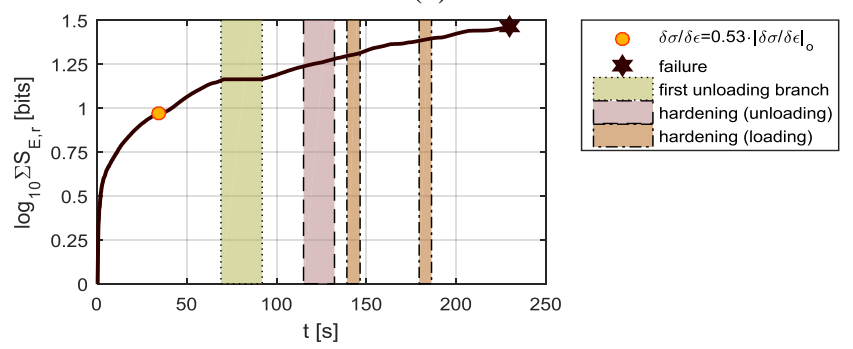

(c)

Figure 9. Relative AE entropies $S_{E, r}$ for tests (a) $C 1$, (b) $C 2$, and (c) $C 3$ highlighting the most significant mechanical/damage stages. $\delta \sigma / \delta \varepsilon$ in (a) represents the stiffness of the branch consequent to the previous tension peak, and $|\delta \sigma / \delta \varepsilon|_{o}$ is the initial stiffness. All damage conditions highlighted in (b) are related to the superior stress-strain envelope.

\subsection{Failure criteria}

The slope of the Shannon entropy decreases as the damage increase, and such parameter always reaches a very reduced value prior to the failure. A value of the tangent lower than a given threshold might be a sufficient condition for defining an incipient failure; moreover, the smooth/regular curve tendency makes the entropy evaluation promising for realtime monitoring purposes. This trend seems not to be depending on the loading condition/program: very similar curve shapes are observed for both monotonic and various cyclic loading conditions. Analogously, the value of the relative entropy is clearly correlated to the incipient failure condition: exceeding threshold values could represent a sufficient condition for failure.

The PBA previously presented is implemented according to this evidence. $\mathrm{EDP}_{1}$ and $\mathrm{EDP}_{2}$ are defined in Equations 7 and 8. It is recalled that EDPs are meant as specific measures associated with the (micro)structural response of the specimens under applied loading conditions.

$$
\begin{gathered}
\mathrm{EDP}_{1}=\frac{\delta\left(\log _{10} \Sigma \mathrm{S}_{\mathrm{E}}\right)}{\delta \mathrm{t}} \\
\mathrm{EDP}_{2}=\log _{10} \Sigma \mathrm{S}_{\mathrm{E}, \mathrm{r}}
\end{gathered}
$$

Failure condition was considered as a unique DS, which was previously defined. Table 3 and Table 4 report the statistical values of $\mathrm{EDP}_{1}$ and EDP related to all considered tests and failure occurring. In particular, $\mu_{x}, \sigma_{x}$, and $C V_{x}$ are mean, standard deviation, and coefficient of variation.

Figure 10 depicts the best-fitting and empirical fragilities related to the monotonic/cyclic tests on pearlitic DCI considering (a) EDP 1 and (b) $\mathrm{EDP}_{2}$. Figure 11 shows the bestfitting and empirical fragilities related to FCG tests on steel and aluminium CTs performed in [29]. The median $\left(x_{m}\right)$ and logarithmic standard deviation $(\beta)$ values are reported in Table 5 and Table 6 . A fragility curve based on a dataset with at least three samples (i.e., all curves in Figures 10 and 11) results in (at least) medium quality level, according to Porter $[35,36]$. However, an additional dispersion might also be added to the best-fit dispersion in order to take into account the reduced number of tests, according to Porter [35,36].

It is recalled that both monotonic and cyclic tests were performed on identical specimens (i.e., microtensile). The monotonic tests were performed considering the same testing/loading conditions, whereas the cyclic tests were conducted through significantly different loading programs (e.g., Figure 4.a). Therefore, the fragility related to the monotonic tests does not account for any variability of the loading conditions. This explains the larger data dispersion evidenced over the cyclic tests: the fragilities related to CTs account for both material and geometrical/loading condition variability. However, the selection of the varied features related to both cyclic tests on DCIs and fatigue tests on CTs was arbitrary, and it cannot be considered to be exhaustive.

The $\mathrm{EDP}_{1}$ fragility curves (i.e., failure probability) decrease as the $\mathrm{EDP}_{1}$ increase according to the experimental evidence, i.e., the slope of the cumulative Shannon entropy monotonically decreases as the damage increase up to the failure. Figure 10 shows that for given values of EDP, monotonic failure has a significantly larger failure probability than cyclic ones. This occurs with regard to both $\mathrm{EDP}_{1}$ and $\mathrm{EDP}_{2}$. In other words, the cyclic loading procedure supplies an overcapacity margin to the material, if the monotonic response is considered as a reference. In particular, $\mathrm{EDP}_{1}$ $\left(\mathrm{EDP}_{2}\right)$ associated with cyclic test fragility is smaller (larger) than monotonic one, over the whole range of probabilities. If $\mathrm{EDP}_{1}$ is considered, cyclic tests produce a smaller logarithmic standard deviation, while this is larger for $\mathrm{EDP}_{2}$ (Tables 5 and 6 ). The clear distinction between monotonic and cyclic data points confirms the reliability of the approach: the features of 
the loading program have a clear influence on the associated EDP values, which is consistent with the two different EDPs.

The fragility curves for both monotonic and cyclic tests (Figure 10) take into account a large variability related to the loading conditions. These curves could represent reals cases: 1) when there is no information about the loading path (not known a priori) or 2) the loads have features of both the monotonic and cyclic tests. Therefore, such fragility curves might represent the spectrum of the potential scenarios that monitored real structures would undergo.

The $\mathrm{EDP}_{1}$ fragility curve related to tests on CTs (Figure 11.a) is defined for extremely low EDP values if compared to the case related the tests on DCIs (Figure 10.a). On the contrary, the fragility curve related to $\mathrm{EDP}_{2}$ (Figure 11.b) is more comparable to the ones associated with DCIs (Figure 10.b). In particular, the FCG tests median value is quite similar to all DCI tests, whereas the logarithmic standard deviation is significantly smaller (Tables 5 and 6). Both failure criteria identified for DCIs also apply to FCG tests. Very low values of the Shannon entropy slope were identified at the failure; they had a reduced dispersion among the different applications. Thresholds of relative entropy were found having values not particularly depending on the specific application and with a reduced dispersion.

\section{Conclusions}

The paper presented an innovative approach for the assessment of fracture damage in ductile cast irons (DCIs). Cyclic tensile tests were performed on microtensile pearlitic DCI specimens to assess the damaging mechanisms by means of scanning electron microscopy (SEM) analysis and acoustic emission (AE) testing.

The micromechanisms occurring under monotonic response were also found under fatigue loading, even though with minor different trends/significance. Both Shannon and Kullback-Leibler AE entropies were computed. The AE entropy evaluation was proven to be reliable for damage detection and failure prediction in DCIs under fatigue loading.

$\mathrm{AE}$ entropies trend and values were found to be not particularly affected by the loading program. The peculiarities related to fatigue response were physically explained by comparing them with the monotonic results. The analysis of the AE activity confirmed that low levels of stress produce microstructural damage, which is associated with the fracture phenomena occurring within the nodules. The violation of the Kaiser effect is consistent with the correlation between the $\mathrm{AE}$ activity and the nodule damage.

Damage correlations based on both entropy formulations were supplied. The slope of Shannon entropy decreases, and the relative entropy increases, as the damage is accumulated. The methodology was particularly efficient regarding failure prediction.
Failure criteria were defined by assessing the developed entropy parameters according to the performance-based approach (PBA) typically used in structural and earthquake engineering. The robustness of the approach was also confirmed by assessing the fragility related to the failure response of DCIs under monotonic loading and fatigue crack growth (FCG) tests on metallic compact tension specimens (CTs).

The failure criteria were confirmed to be promising for health monitoring purposes. The presented approach, as well as the defined failure criteria, will have a significant impact on the current state of the art about AE testing in metallic components. The combined real-time assessment of $\mathrm{EDP}_{1}$ and $\mathrm{EDP}_{2}$ can enhance health monitoring approaches, and it would cover the whole damage process since $\mathrm{EDP}_{1}$ is able to detect the damage evolution, while $\mathrm{EDP}_{2}$ is capable of predicting the incipient failure.

The study can be considered as a reference for similar applications, and it can inspire the definition of innovative monitoring protocols based on the real-time entropy assessment. The robustness was proved by both the validity of the approach and the reliability of the results for different loading conditions and materials/tests. Since both EDPs were found to be well correlated to the failure occurring, a multivariate fragility assessment could enhance the efficiency of the fragility fitting.

The findings of the presented study can be generalised by increasing the number of tests. Moreover, the fragility curves can also be extended to other components of the same material in order to provide more robust performance parameters in SHM implementations.

\section{Acknowledgements}

The experimental testing was partially funded by Seedling 2016, REF 2016/2017, REF 2017/18 funds (Dr M Ercolino, University of Greenwich, UK). The AE equipment was produced by Mistras LTD UK. The insightful discussions with Dr Stefan Zigan and Dr Panos Kloukinas are fully acknowledged.

\section{References}

[1] Rodenas-Herráiz D, Xu X, Fidler P R A and Soga K 2019 Power-efficient piezoelectric fatigue measurement using longrange wireless sensor networks Smart Mater. Struct. 28 095004

[2] Vagnoli M, Remenyte-Prescott R and Andrews J 2018 Railway bridge structural health monitoring and fault detection: State-of-the-art methods and future challenges Struct. Health Monit. 17 971-1007

[3] Aygül M, Bokesjö M, Heshmati M and Al-Emrani M 2013 A comparative study of different fatigue failure assessments of welded bridge details Int. J. Fatigue 49 62-72 


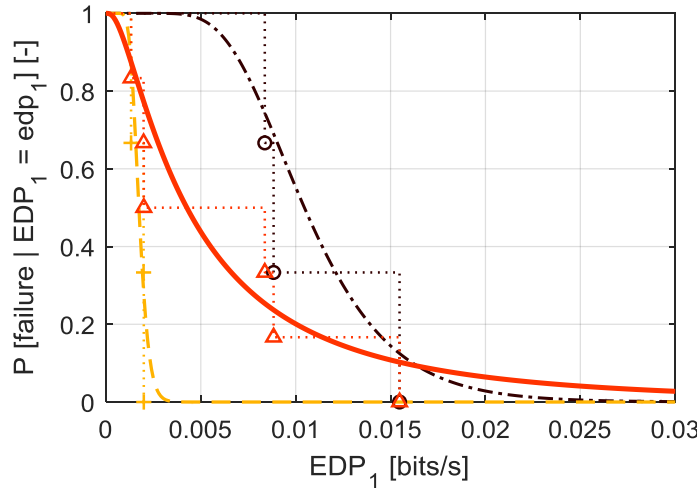

(a)

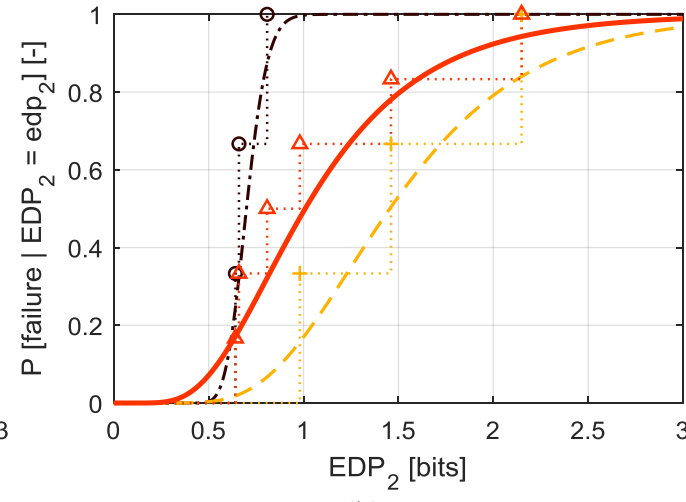

(b)

Figure 10. Best-fitting and empirical fragility curves related to the monotonic/cyclic tests on pearlitic DCI considering (a) $\mathrm{EDP}_{1}$ and (b) $\mathrm{EDP}_{2}$.

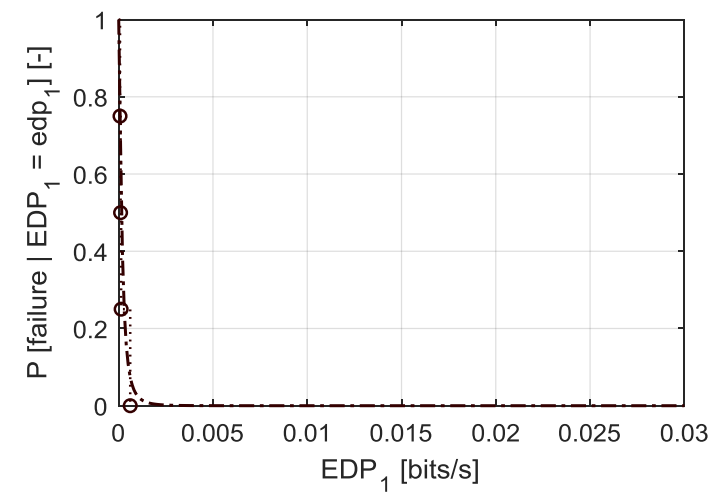

(a)

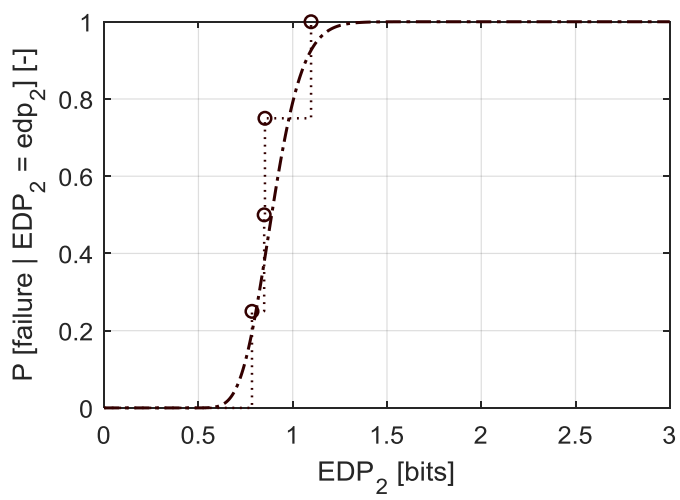

(b)

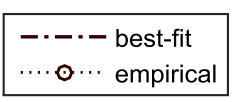

Figure 11. Best-fitting and empirical fragility curves related to FCG tests on steel and aluminium CTs considering (a) $\mathrm{EDP}_{1}$ and (b) $\mathrm{EDP}_{2}$.

Table 3. Statistical values of $\operatorname{EDP}_{1}$ related to all considered case studies with regard to failure DS.

\section{EDP1}

\begin{tabular}{llll}
\cline { 2 - 3 } Test & $\boldsymbol{\mu}_{\boldsymbol{x}}$ & $\boldsymbol{\sigma}_{\boldsymbol{x}}$ & $\boldsymbol{C V}_{\boldsymbol{x}}$ \\
\cline { 2 - 4 } & {$[$ bits s-1] } & {$[$ bits s-1] } & {$[-]$} \\
\hline monotonic tests on pearlitic DCI [9] & $1.09 \times 10^{-2}$ & $4.00 \times 10^{-3}$ & $3.66 \times 10^{-1}$ \\
\hline cyclic tests on pearlitic DCI & $2.9 \times 10^{-3}$ & $1.9 \times 10^{-3}$ & $6.68 \times 10^{-1}$ \\
\hline FCG tests on steel/aluminium CTs [29] & $2.27 \times 10^{-4}$ & $2.57 \times 10^{-4}$ & $1.13 \times 10^{0}$ \\
\hline
\end{tabular}

Table 4. Statistical values of $\mathrm{EDP}_{2}$ related to all considered case studies with regard to failure DS.

\begin{tabular}{llll}
\hline \multirow{2}{*}{ Tests } & \multicolumn{2}{l}{ EDP2 } & $\boldsymbol{\sigma}_{\boldsymbol{x}}$ \\
\cline { 2 - 4 } & $\boldsymbol{\mu}_{\boldsymbol{x}}$ & {$[$ bits] } & {$[-]$} \\
\cline { 2 - 4 } & {$[$ bits] } & $9.15 \times 10^{-2}$ & $1.30 \times 10^{-1}$ \\
\hline monotonic tests on pearlitic DCI [9] & $7.03 \times 10^{-1}$ & $4.32 \times 10^{-2}$ & $5.10 \times 10^{-2}$ \\
\hline cyclic tests on pearlitic DCI & $8.48 \times 10^{-1}$ & $1.38 \times 10^{-1}$ & $1.54 \times 10^{-1}$ \\
\hline FCG tests on steel/aluminium CTs [29] & $8.96 \times 10^{-1}$ &
\end{tabular}


Table 5. Median $\left(x_{m}\right)$ and logarithmic standard deviation $(\beta)$ values corresponding to best-fit fragility curves considering EDP 1 .

\begin{tabular}{lll}
\hline \multirow{2}{*}{ Test } & \multicolumn{2}{l}{ EDP } \\
\cline { 2 - 3 } & $x_{m}$ & $\beta$ \\
\cline { 2 - 3 } & {$[$ bits s-1] } & {$[-]$} \\
\hline monotonic tests on pearlitic DCI & $1.05 \times 10^{-2}$ & $3.40 \times 10^{-1}$ \\
\hline cyclic tests on pearlitic DCI & $1.74 \times 10^{-2}$ & $2.35 \times 10^{-1}$ \\
\hline (all) tests on pearlitic DCI & $4.26 \times 10^{-3}$ & $1.01 \times 10^{0}$ \\
\hline FCG tests on steel/aluminium CTs & $1.53 \times 10^{-4}$ & $9.58 \times 10^{-1}$ \\
\hline
\end{tabular}

Table 6. Median $\left(x_{m}\right)$ and logarithmic standard deviation $(\beta)$ values corresponding to best-fit fragility curves considering $\mathrm{EDP}_{2}$.

\begin{tabular}{lll}
\hline \multirow{2}{*}{ Test } & \multicolumn{2}{l}{ EDP2 } \\
\cline { 2 - 3 } & $x_{m}$ & $\beta$ \\
\cline { 2 - 3 } & {$[$ bits] } & {$[-]$} \\
\hline monotonic tests on pearlitic DCI & $6.99 \times 10^{-1}$ & $1.26 \times 10^{-1}$ \\
\hline cyclic tests on pearlitic DCI & $1.45 \times 10^{-0}$ & $3.92 \times 10^{-1}$ \\
\hline (all) tests on pearlitic DCI & $1.01 \times 10^{-0}$ & $4.79 \times 10^{-1}$ \\
\hline FCG tests on steel/aluminium CTs & $8.88 \times 10^{-1}$ & $1.46 \times 10^{-1}$ \\
\hline
\end{tabular}

[4] Wong L, Rathnayaka S, Chiu W K and Kodikara J 2018 Utilising hydraulic transient excitation for fatigue crack monitoring of a cast iron pipeline using optical distributed sensing Struct. Control Health Monit. 25 e2141

[5] Iacoviello F, Di Bartolomeo O, Di Cocco V and Piacente V 2008 Damaging micromechanisms in ferritic-pearlitic ductile cast irons Mater. Sci. Eng. A 478 181-6

[6] Bellini C, Di Cocco V, Favaro G, Iacoviello F and Sorrentino L 2019 Ductile cast irons: Microstructure influence on the fatigue initiation mechanisms Fatigue Fract. Eng. Mater. Struct. 42 2172-82

[7] Iacoviello F, Di Cocco V, Rossi A and Cavallini M 2015 Fatigue crack tip damaging micromechanisms in pearlitic ductile cast irons Fatigue Fract. Eng. Mater. Struct. 38 23845

[8] D'Angela D, Ercolino M, Bellini C, Di Cocco V and Iacoviello F 2020 Analysis of acoustic emission entropy for damage assessment of ductile cast irons Mater. Des. Process. Commun.

[9] D'Angela D, Ercolino M, Bellini C, Di Cocco V and Iacoviello F 2020 Characterisation of the damaging micromechanisms in a pearlitic ductile cast iron and damage assessment by acoustic emission testing Fatigue Fract. Eng. Mater. Struct.

[10] Ai Y, Sun C and Zhang W 2018 Life prediction of the tensile damage progress for high-speed train gearbox shell based on acoustic emission sensor and an automatic optimisation method Int. J. Distrib. Sens. Netw. 14155014771878145
[11] Carpinteri A, Lacidogna G, Accornero F, Mpalaskas A C, Matikas T E and Aggelis D G 2013 Influence of damage in the acoustic emission parameters Cem. Concr. Compos. 44 9-16

[12] Aggelis D G, Kordatos E Z and Matikas T E 2011 Acoustic emission for fatigue damage characterisation in metal plates Mech. Res. Commun. 38 106-10

[13] Carpinteri A, Lacidogna G and Niccolini G 2011 Damage analysis of reinforced concrete buildings by the acoustic emission technique Struct. Control Health Monit. 18 660-73

[14] Kong X, Li J, Collins W, Bennett C, Laflamme S and Jo H 2017 A large-area strain sensing technology for monitoring fatigue cracks in steel bridges Smart Mater. Struct. 26085024

[15] Ebrahimkhanlou A and Salamone S 2017 A probabilistic framework for single-sensor acoustic emission source localisation in thin metallic plates Smart Mater. Struct. 26 095026

[16] Ercolino M, Farhidzadeh A, Salamone S and Magliulo G 2015 Detection of onset of failure in prestressed strands by cluster analysis of acoustic emissions Struct. Monit. Maint. 2 339-55

[17] Lin L and Chu F 2011 Approximate entropy as acoustic emission feature parametric data for crack detection Nondestruct. Test. Eval. 26 119-28

[18] Bhuiyan M Y and Giurgiutiu V 2018 The signatures of acoustic emission waveforms from fatigue crack advancing in thin metallic plates Smart Mater. Struct. 27015019 
[19] Chai M, Zhang Z and Duan Q 2018 A new qualitative acoustic emission parameter based on Shannon's entropy for damage monitoring Mech. Syst. Signal Process. 100 617-29

[20] Kahirdeh A and Khonsari M 2016 Acoustic Entropy of the Materials in the Course of Degradation Entropy 18280

[21] Al-Jumaili S K J 2016 Damage Assessment In Complex Structures Using Acoustic Emission

[22] Carpenter S H and Zhu Z 1991 Correlation of the acoustic emission and the fracture toughness of ductile nodular cast iron J. Mater. Sci. 26 2057-62

[23] Shen G, Li L and Wu Z 2012 Study on the Characteristics of Acoustic Emission for Grey Cast Iron 30th European Conference on Acoustic Emission Testing \& 7th International Conference on Acoustic Emission University of Granada, 1215 September 2012

[24] Sjögren T and Svensson I L 2005 Studying elastic deformation behaviour of cast irons by acoustic emission Int. J. Cast Met. Res. 18 249-56

[25] Kietov V, Henschel S and Krüger L 2018 Study of dynamic crack formation in nodular cast iron using the acoustic emission technique Eng. Fract. Mech. 188 58-69

[26] Kietov V, Henschel S and Krüger L 2019 AE analysis of damage processes in cast iron and high-strength steel at different temperatures and loading rates Eng. Fract. Mech. 210 $320-41$

[27] Shannon C E 1948 A Mathematical Theory of Communication Bell Syst. Tech. J. 27 379-423

[28] Hoffmann M J, Hammer M, Endriss A and Lupascu D C 2001 Correlation between microstructure, strain behavior, and acoustic emission of soft PZT ceramics Acta Mater. 49 130110

[29] D'Angela D and Ercolino M 2019 Acoustic Emission Entropy as a fracture-sensitive feature for real-time assessment of metal plates under fatigue loading Procedia Struct. Integr. 18 570-6

[30] Kahirdeh A, Sauerbrunn C, Yun H and Modarres M 2017 A parametric approach to acoustic entropy estimation for assessment of fatigue damage Int. J. Fatigue 100 229-37

[31] Sauerbrunn C, Kahirdeh A, Yun H and Modarres M 2017 Damage Assessment Using Information Entropy of Individual Acoustic Emission Waveforms during Cyclic Fatigue Loading Appl. Sci. 7562

[32] Unnthorsson R, Runarsson T P and Jonsson M T 2008 AE entropy for the condition monitoring of CFRP subjected to cyclic fatigue $J$ Acoust Emiss 262-70.

[33] Kullback S and Leibler R A 1951 On Information and Sufficiency Ann. Math. Stat. 22 79-86

[34] Karimian S F, Modarres M and Bruck H A 2020 A new method for detecting fatigue crack initiation in aluminum alloy using acoustic emission waveform information entropy Eng. Fract. Mech. 223106771

[35] Porter K, Kennedy R and Bachman R 2007 Creating Fragility Functions for Performance-Based Earthquake Engineering Earthq. Spectra 23 471-89

[36] Porter K, Kennedy R and Bachman R 2006 Developing fragility functions for building components for ATC-58. A Report to ATC-58. (Applied Technology Council, Redwood City, CA, USA)

[37] Kasvayee K A, Salomonsson K, Ghassemali E and Jarfors A E W 2016 Microstructural strain distribution in ductile iron; comparison between finite element simulation and digital image correlation measurements Mater. Sci. Eng. A 655 27-35

[38] Grosse C and Ohtsu M 2008 Acoustic Emission Testing (Berlin: Springer Berlin Heidelberg)

[39] Iacoviello F, Di Cocco V and Piacente V 2006 Brevetto "FR2006A00026". Macchina automatica per morsetta estraibile per prove di trazione su mini provini: morsetta posizionabile all'interno della camera di un microscopio elettronico a scansione SEM

[40] Beattie A 2013 Acoustic emission non-destructive testing of structures using source location techniques.

[41] Mistras LTD UK. https://mistrasgroup.co.uk/

[42] Di Cocco V, Iacoviello F and Cavallini M 2010 Damaging micromechanisms characterisation of a ferritic ductile cast iron Eng. Fract. Mech. 77 2016-23

[43] ATC-58 Structural Performance Products Team 2004 ATC-58 Project Task Report Phase 2, Task 2.2 Engineering Demand Parameters for Structural Framing Systems (201 Redwood Shores Parkway, Suite 240 Redwood City, California 94065: Applied Technology Council)

[44] Cosenza E, Iervolino I and Manfredi G 2004 On Ground Motion Duration and Engineering Demand Parameters International Workshop on Performance-Based Seismic Design (Bled (Slovenia): Berkeley, Calif. : Pacific Earthquake Engineering Research Center, 2004.) pp 309-20

[45] Stocchi A and Richard B 2019 Sensitivity of engineering demand parameters as a function of structural typology and assessment method Nucl. Eng. Des. 343 151-65

[46] Cornell C A 1968 Engineering seismic risk analysis Bull. Seismol. Soc. Am. 58 1583-606

[47] Rosowsky D V and Ellingwood B R 2002 Performance-Based Engineering of Wood Frame Housing: Fragility Analysis Methodology J. Struct. Eng. 128 32-8

[48] Ellingwood B R 1994 Probability-based codified design: past accomplishments and future challenges Struct. Saf. 13 159-76

[49] Kaiser J 1950 Untersuchungen über das Auftreten von Geräuschen beim Zugversuch

[50] Guarino A, Garcimartín A and Ciliberto S 1998 An experimental test of the critical behaviour of fracture precursors Eur. Phys. J. B 6 13-24 